https://artnodes.uoc.edu

\title{
Imaginación radical y anacronía de las imágenes: radios libres y vídeo comunitario en España
}

\author{
Ignasi Gozalo Salellas \\ Universitat Oberta de Catalunya \\ Bryn Mawr College
}

Fecha de presentación: octubre de 2021

Fecha de aceptación: enero de 2022

Fecha de publicación: enero de 2022

\section{Cita recomendada}

Gozalo Salellas, Ignasi. 2022. «Imaginación radical y anacronía de las imágenes: radios libres y vídeo comunitario». En: Garcés, Marina (coord.). «Ecología de la imaginación». Artnodes, no. 29. UOC. [Fecha de consulta: dd/mm/aa]. https://doi.org/10.7238/artnodes.v0i29.393020

Cos textos publicados en esta revista están sujetos -si no se indica lo contrario- a una licencia
SOMER Reconocimiento 4.0 Internacional de Creative Commons. La licencia completa se puede consultar
en https://creativecommons. org/licenses/by/4.0/deed.es

\section{Resumen}

Este ensayo presenta las prácticas de comunicación comunitarias que se produjeron en los años setenta en España e Italia como experiencias de pedagogía e imaginación radical. Se propone la imaginación radical anacrónica como el aprendizaje que nos ofrece el montaje de diferentes experiencias de creación colectiva a través del tiempo y a partir de la memoria del pasado. Es una forma de combatir los límites de la imaginación en el tiempo póstumo actual (Garcés 2019). Esta imaginación radical no se interesa por la representación de las imágenes, sino que se detiene en el carácter constitutivo de los actos imaginativos que las comunidades de práctica producen en la sociedad. El pensador Cornelius Castoriadis lo definiría como instituciones transformadoras.

Poco se han estudiado las prácticas autónomas de comunicación que se dieron en los años setenta y ochenta en España. En España, algunas prácticas de mesocomunicación caracterizadas por ser de bajo coste, descentralizadas, locales, plurales y de servicio social (Gubern 1985), tales como el vídeo comunitario y las radios libres, propusieron caminos alternativos al horror vacui cultural e 


\title{
artnodes
}

https://artnodes.uoc.edu

Imaginación radical y anacronía de las imágenes: radios libres y vídeo comunitario en España

institucional de esos años transicionales. Importando elementos de movimientos socioculturales anglosajones y de Europa, las experiencias de Video-Nou o Radio Alice se basaron en la noción de prototipo como herramienta pedagógica para la transformación social, local y situada, más que en la producción artística o comunicativa. Serían prácticas del «do it ourselves».

\section{Palabras clave}

imaginación radical; anacronismo; distopía; prácticas comunitarias; vídeo comunitario; radios libres

\section{Radical imagination and anachronism of images: free radio and community video in Spain}

\begin{abstract}
This essay presents the practices of community communication that took place in the 70s in Spain and Italy as experiences of pedagogy and of radical imagination. Anachronistic radical imagination is proposed as the learning offered to us by the set of various experiences of collective creation over time and based on past memory. It is a way to combat the limits of the imagination and current posthumous time (Garcés 2019). This radical imagination is not concerned with the representation of images, but rather stops on the constitutive nature of the imaginative acts that practical communities produce in society. The thinker Cornelius Castoriadis would define it as transformative institutions.

The autonomous communication practices that emerged in the 70s and 80s in Spain have not been studied widely. In Spain, some mesocommunication practices characterized by their low cost and decentralized, local, plural, and social service nature (Gubern 1985), such as community video and free radio proposed paths alternative to the cultural and institutional horror vacui of those transitional years. Importing elements of Anglo-Saxon and European sociocultural movements, the experiences of Video-Nou or Radio Alice were based on the notion of a prototype as a pedagogical tool for social, local, and situated transformation, more than on artistic or communicative production. They would be "do it ourselves" practices.
\end{abstract}

\section{Keywords}

radical imagination; anachronism; dystopia; community practices; community video; free radio 


\section{artnodes}

https://artnodes.uoc.edu

Imaginación radical y anacronía de las imágenes: radios libres y vídeo comunitario en España

\section{Introducción: imaginar contra el tiempo agonístico}

Hay un cierto consenso en que atravesamos un tiempo sin horizontes de futuro. 0 así se nos cuenta. La distopía de nuestro tiempo se caracteriza por su carácter angustiante: hay una falta creciente de expectativas colectivas que se ha trasladado al ámbito de lo privado, entre el aislamiento y el egoísmo. Si la violencia y el autoritarismo fueron el pecado original de las utopías de emancipación del siglo xx, la privatización del derecho al futuro pone en evidencia la naturaleza de la última utopía que el mundo ha ofrecido: la utopía neoliberal, ilimitada y liberadora, empeñada en robarnos la idea de progreso y emancipación colectiva.

Lo ha hecho, como bien nos recordaba Zygmunt Bauman en Retrotopía (Bauman 2017), privatizándola y expoliándola del mundo que habitamos. En su obra póstuma, Bauman nos alertaba del peligro de nuestra reacción ante esa tiranía: la retrotopía, es decir, una relación con la utopía llena de nostalgia en un doble sentido. Por un lado, un sentimiento de pérdida - de un pasado mejor, a menudo inexistente- $y$, al mismo tiempo, el anhelo de una fantasía personal en medio de un mundo totalmente fragmentado. Dicho en términos freudianos, hoy no somos capaces de pensar la utopía sino como un mecanismo de defensa, de salvación. ${ }^{1}$ Ante esto, sobrevivir y acatar devienen las dos únicas estrategias en el manual de instrucciones de una vida delegada, no vivida.

En Melancolía de izquierda: Después de las utopías (2019), Enzo Traverso historiza con precisión el cambio de paradigma que sufrimos en el tiempo contemporáneo, atravesado por lo que Reinhart Koselleck definió como sattelzeit. ${ }^{2}$ «un "tiempo encabalgado", un tiempo de paso» (Traverso 2019, 26). Para Traverso, la temporalidad que comprende desde la crisis del marxismo de finales de los años setenta hasta el 11 de septiembre de 2001 representa la transición hacia un nuevo «paisaje político e intelectual. La caída del Muro de Berlín simboliza una transición en la cual se fusionan unas con otras formas viejas y nuevas» (Traverso 2019, 27) y, por consiguiente, con un nuevo léxico que para Traverso se sintetiza en dos conceptos: el mercado y la competencia,

"las piedras angulares del léxico neoliberal- se convirtieron en los fundamentos "naturales" de las sociedades postotalitarias. Colonizaron nuestra imaginación y dieron forma a un nuevo habitus antropológico, como los valores dominantes de una nueva "conducción de la vida" (Lebensführung) frente a la cual el viejo ascetismo protestante de una clase burguesa guiada por la ética -conforme al clásico retrato de Max Weber- parece un vestigio arqueológico» (Traverso 2019, 27).

Ahora que la nebulosa de oscuridad y la histeria contra el tiempo dejadas por el neoliberalismo nos invaden, el papel de la creación ya no debería ser tanto producir ficción como realidad. Abocarnos a la imaginación es despojarnos de la fantasía y optar por el camino no tanto del futuro como del horizonte de posibilidades. Para ello, un camino de futuro podría ser aprender de prácticas imaginativas de temporalidades diferentes a la nuestra, porque la distopía nos anula el derecho al futuro y la retrotopía nos ahoga en la nostalgia, que no es otra cosa que la memoria castradora.

\section{Una imaginación radical anacrónica}

Contra la distopía agonística contemporánea, la imaginación anacrónica proporciona oxígeno al presente a la vez que corrige el pecado melancólico de la retrotopía. Si bien el arte ha cumplido históricamente un valor prometeico -ha imaginado, visualizado y estimulado ideas emancipadoras-, el arte de nuestro tiempo -eminentemente visual, sonoro, multimedia, virtual, interactivo- ha mutado hacia una condición predictiva. Lo que hace unas décadas, en los albores de la transición neoliberal que denuncia Traverso, fueron relatos apocalípticos a través de géneros como la ciencia ficción y el fantástico, hoy son la pura realidad. Incluso las series, los videojuegos y otras formas de cultural visual como el cómic acosan nuestro sentido de la existencia con tramas distópicas.

Si en la actualidad vivimos a la espera de nuevas formas de imaginación, aturdidos por imágenes que nos anuncian el fin de lo posible y atrapados por un sentido de cierre, los años setenta fueron los años de la invención de prácticas comunitarias basadas en la imaginación radical -tal y como el filósofo Cornelius Castoriadis la definió. ${ }^{3}$ Esa pulsión comunitarista y radical se dio tanto en el ámbito de lo político-social como en la creación -ya fuera en el arte, la comunicación 0 las pedagogías más innovadoras-. Este ensayo precisamente entrelaza esos dos ejes -lo social con lo creador- en el marco de los espacios autónomos surgidos en Italia y España en los años setenta.

Román Gubern describió como «mesocomunicativas» (Gubern 1985), de bajo coste, descentralizadas, locales, plurales y con servicio social aquellas prácticas de comunicación alternativas que se dieron en Barcelona a finales de los años setenta a imagen de las de Bolonia al principio de la misma década. Las prácticas de imaginación radical anacrónica no vinculan el pasado con el presente, sino que atraviesan todas las temporalidades para imaginar el futuro. Son imágenes de una memoria discontinua que se alejan de la rigidez de la historia. Son imágenes que rehúyen los datos, la genealogía y la interpretación. Por el contrario, se abocan a la creación de nuevos imaginarios. La anacronía de estas imágenes radicales recae en su carácter dialéctico: nos interpelan y nos obligan a no decaer en un momento de discurso agonístico y, a la vez, a pensar dónde están los espacios para imaginar

1. También Marina Garcés (Garcés 2019) ha teorizado el tiempo póstumo como la imposibilidad emancipatoria a través del relato del colapso, ya sea con el anuncio de la catástrofe o la salvación

2. Koselleck se refiere al periodo entre la crisis del Antiguo Régimen y la Restauración. Traverso, al impasse entre la última modernidad y el supuesto fin de la historia, que anunciaría Francis Fukuyama.

3. Fundamentalmente, en dos obras: La institución imaginaria de la sociedad(Buenos Aires: Tusquets Editores, 2007) y Ontología de la creación (Santa Fe de Bogotá: Ensayo y error, 1997, 132-212). 


\section{artnodes}

https://artnodes.uoc.edu

Imaginación radical y anacronía de las imágenes: radios libres y vídeo comunitario en España

radicalmente el hoy. Se trata de actualizar el sentido de la dialéctica contracorriente de Walter Benjamin; esto es, pensar un presente entendido como montaje de las imágenes divergentes que nos llegan de la memoria, no del pasado. Georges Didi-Huberman diferencia apropiadamente ambos conceptos en Ante el tiempo. Historia del tiempo y anacronismo de las imágenes (Didi-Huberman 2008, 60):

«Es ella [la memoria] la que decanta el pasado de su exactitud. Es la memoria lo que el historiador convoca e interroga, no exactamente "el pasado". No se puede aceptar la dimensión memorativa de la historia sin aceptar, al mismo tiempo, su anclaje en el inconsciente y su dimensión anacrónica.»

Las prácticas de vídeo comunitario y radio libre estudiadas -Video-Nou y Radio Alice- se resisten a ser enterradas por la economía de las imágenes que nos hostiga y reemergen como un saber histórico radical gracias a la función de un montaje que pone en relación varios archivos heterogéneos, únicos, vividos: «las imágenes chocan entre sí para que surjan las palabras, entran en colisión para que visualmente tenga lugar el pensamiento (...). El montaje es el arte de producir esta forma que piensa. Es el arte de reflejar la imagen dialéctica» (Didi-Huberman 2004, 205). Así, las prácticas autónomas de los años setenta e inicios de los ochenta en España o Italia se sitúan en el lado de la excepción histórica del péndulo dialéctico entre normalidad y excepcionalidad, y del que fenómenos tan variados como el movimiento okupa, los indignados, la objeción de conciencia o la ola feminista en España y el movimiento Tute Bianche en Italia son otras expresiones.

Todas ellas forman parte de una cadena de imágenes en un sentido radical; esto es, como espacios de creatividad producidos por prácticas concretas. Castoriadis, en «Imaginación, imaginario, reflexión» (Castoriadis 1997, 132-133), aporta un doble sentido interesante del término imaginación: si la imaginación segunda es aquella que reproduce imágenes en el contexto de la comunicación de masas («imaginación simplemente reproductiva y/o combinatoria»), la imaginación primera o radical se refiere a «la idea de invención, o mejor y hablando propiamente, de creación» (Castoriadis 1997, 132). Hoy procesamos el testimonio de las imágenes y los sonidos de aquellas experiencias como imaginación segunda, pero debemos reivindicar la influencia de esas experiencias en posibilidades contemporáneas a través del reconocimiento mutuo y como legado de la imaginación radical. Esta imaginación huye de la representación de las imágenes y se detiene en el carácter constitutivo de los actos imaginativos que las comunidades de práctica producen y que Cornelius Castoriadis definió como instituciones transformadoras. Como el propio Castoriadis remataría, «es porque hay imaginación radical e imaginario instituyente que hay para nosotros "realidad"» (Castoriadis 1997, 133). Con ello, Castoriadis hace una contribución básica: abandonar el paradigma de la imaginación como facultad individual, ya en Aristóteles o Kant, para pensar el paradigma de imaginario como producción social y colectiva que «crea ex nihilo» (lbíd.), de la nada.

\section{Máquinas imaginativas no homologadas}

Esas prácticas de mesocomunicación aparecen en los años setenta como respuesta al impasse cultural de los viejos regímenes políticos. El intercambio de opiniones y sacar partido de los nuevos soportes mediáticos que llegaban al mercado en ese tiempo fueron algunas de las características para una exitosa participación social y ciudadana. Se erigen en espacios de proximidad, de acción directa y culturalmente transversales, lo cual les permite experimentar con nuevos lenguajes y formatos que la oficialidad ni conoce. Es por ello por lo que Franco Berardi, junto a Marco Jacquemet y Giancarlo Vitali (2003), definieron las experiencias equivalentes en Italia como «máquinas imaginativas no homologadas».

Las estaciones de radio libre, los colectivos de vídeo comunitario y las estaciones de la llamada «guerrilla television» 4 se multiplicaron rápidamente por los países del primer mundo a finales de los años sesenta. Solo en Nueva York, a lo largo de los años setenta, se dieron un sinfín de colectivos de vídeo, como People's Video Theater, TVTV, Videofreex, Video Free America, Videopolis o Portable Channel. Sin olvidar las prácticas con vídeo del arte conceptual, las nuevas prácticas comunitarias se servían de las posibilidades comunicativas que dos nuevas tecnologías de principios de los años sesenta aportaron al campo de lo social: la videografía y las radios no comerciales, ambas de carácter autogestionado y a menudo comunitarios. Compartían dos características: la portabilidad y la autoproducción, y respondían a la crisis de valores de la sociedad moderna, que Félix Guattari apuntaría como la crisis de los medios de comunicación de masas, siendo «profundamente pluralista, pluricéntrico y heterogéneo, de la subjetividad contemporánea, a pesar de la homogeneización de la que es objeto a causa de su producción sometida a los medios de comunicación de masas (...). Un individuo es ya un "colectivo" de componentes heterogéneas (...). A esto último hay que añadir todos los procedimientos de subjetivación que se encarnan en la palabra, la escritura, la informática, las máquinas tecnológicas» (Guattari 2004, 124).

Se crean las condiciones para una mezcla de los campos de la semiótica, el arte y la información. Para ello, será imprescindible el papel emancipador que tuvieron las nuevas tecnologías de esos dispositivos portables, autogestionables y capaces de mezclarse entre ellos para lograr nuevas e imprevisibles capacidades. En los grupos de vídeo comunitario catalán, por ejemplo, participaban desde ingenieros y arquitectos que diseñaban las instalaciones técnicas hasta sociólogos y periodistas. Lo mismo pasaría con las radios libres, en las que se unían estudiantes con mecánicos 0 ingenieros con pedagogos. Así,

4. Este término fue introducido por Michael Shamberg, una de las principales figuras de la Raindance Corporation durante los años sesenta. El término, que tuvo gran éxito y animó a su aplicación no solo en Estados Unidos, sino también en Canadá, Francia y otros países europeos, incitaba a una guerrilla cultural contra las dos hegemonías de la época, el Estado y el capitalismo. 


\section{artnodes}

https://artnodes.uoc.edu

Imaginación radical y anacronía de las imágenes: radios libres y vídeo comunitario en España

Guattari definiría las prácticas mediáticas alternativas italianas como infradisciplinas resistentes de "conquista del presente gracias a un medio de comunicación» (Berardi et al. 2003, 35). Berardi, Jacquemet y Vitali reducen a tres los medios que harían posible el producto semiótico: el offset, la radio y la cinta de vídeo. Guattari destaca el carácter heterogéneo y no imitativo de esas prácticas:

«Esta apertura será posible gracias a una auténtica heterogénesis de las situaciones colectivas, en la que el aprendizaje ya no se hará por imitación, sino por exploración de lo diferente, constitución progresiva de lo uno en la novedad de lo otro (...). Se afirmarán nuevos saberes en paralelo a la ciencia producida en los laboratorios y las universidades (...)» (Berardi et al. 2003, 37).

En paralelo a las experiencias de vídeo comunitario, otro fenómeno potente serán las radios libres, cuyo principal objetivo fue abrir el micrófono a todas aquellas personas con algo que decir a la comunidad. Las radios libres serán aquello que Brecht reclamaba del medio radiofónico en «Teoría de la radio» (Bassets 1981): no solo un modelo de medio comunicativo, sino antes que nada un movimiento social que se opone a la comunicación vertical, pasiva y alienante como modo de representación social. Proponen modelos de comunicación horizontal, crítica y representativa de los espacios marginales de la sociedad. Por otro lado, luchan contra los monopolios informativos (en sus inicios, estatales; posteriormente, privados) y a favor de la alianza entre grupos autónomos y sociedad civil.

\section{El laboratorio italiano de los setenta}

En Italia, el movimiento revolucionario de la autonomía vio cómo se desarrollaba alrededor suyo toda una serie de prácticas de laboratorio en el ámbito de la cultura y la comunicación. Ya en una fase avanzada, entre 1973 y 1979, abandonó la fábrica y se insertó en la sociedad como una forma de vida. Como recordarían Michael Hardt y Toni Negri, «el antagonismo entre el trabajo y el capital, que se había desarrollado en el interior de la fábrica, investía ahora todas las formas de interacción social. Estudiantes, obreros, grupos de desocupados y otras fuerzas sociales y culturales experimentaban con nuevas formas democráticas de organización social y de acción política en redes horizontales, no jerárquicas» (Hardt y Negri, 2003). Se reivindica la autonomía de la esfera social respecto del Estado y del capital desarrollando la noción de autovaloración. Se sustituye la producción de plusvalía por los deseos colectivos de comunidad. Ejemplos de ello serían las televisiones locales y radios libres.

El origen de las radios libres italianas se remonta al bienio 19681969 , y su propósito inicial es denunciar aspectos concretos de las condiciones de vida de las habitantes locales. ${ }^{5}$ En los años setenta el movimiento se extiende ya por Europa y en Italia se diversifican las experiencias -protagonizadas por grupos ecologistas, autónomos, co- lectivos demócrata-cristianos y grupos de extrema izquierda-. La transversalidad del fenómeno evidencia un deseo sociológico de colectivizar la experiencia. Félix Guattari argumenta que esa capacidad de difusión se debe a un deseo por inventar nuevos medios y por «una tendencia irrefrenable de pasar a la acción» (Bassets 1981, 234). Se trata de «sistemas miniaturizados que ofrecen la posibilidad de una apropiación colectiva de los medios de comunicación, que no sólo los facilitan a las "amplias masas", sino también a las minorías, a los marginales, a los grupos desviados de todo tipo» (Bassets 1981, 231).

Estas guerrillas cotidianas de las ondas no proponen un modelo de contrainformación, sino que ensayan nuevas formas comunicativas que pasan por una gestión diferente del proceso: «por un lado, un centralismo, un conformismo, una opresión (...), por otro, la perspectiva de nuevos espacios de libertad, de autogestión, de expansión de las peculiaridades del deseo (...). Del enfrentamiento con el poder, ha sido "el medio pobre" el que se ha impuesto por su propio peso" (Bassets 1981, 231-232). Guattari, para explicar la expansión rizomática de las emisoras libres, destaca el papel de la técnica no solo como factor de democratización de uso, sino como dilema técnico-político: «la técnica depende de la inventiva, del bricolage de sus promotores (...). El conjunto de medios técnicos y humanos permite establecer un verdadero sistema de feed-back: a través de intervenciones en directo por teléfono, 0 abriendo las puertas del "estudio"». Las innovaciones técnico-políticas de estas emisoras fueron constantes, y posteriormente fueron adoptadas por las cadenas radiofónicas oficiales.

En una línea similar, en «Una nueva era en la libertad de expresión», Umberto Eco proponía la creatividad de estas radios como una gran revolución: «han lanzado la nueva figura del corresponsal con fichas de teléfono. Es un chico cualquiera, que entra en un bar, pide diez fichas e informa en directo a la radio de lo que está viendo. Nos hallamos ante un periodismo de lo instantáneo» (Bassets 1981, 212). La inmediatez del testimonio común, que empieza con el uso de las cabinas telefónicas y las conexiones precarias en directo, modifica los espacios de enunciación. Al pasar del estudio como espacio aislado a convertir lo real en el espacio comunicativo, se transforma la dimensión de aparato a máquina, en tanto que "prolongación de nuestros órganos sensoriales» (Bassets 1981, 217). Su principal logro sería desplazar la mirada moderna del autor hacia una producción acéfala sin dirección que pusiera en cuestión la figura del protagonista -que Félix Guattari determinaría como rasgo común de militantes y modernistas, a los que define como «especialistas de la consigna»-:

«mientras, las radios libres van en el sentido contrario (...) lo que en ellas resulta específico son las soluciones colectivas de enunciación que absorben y "atraviesan" las especializaciones (...). Supone un peligro para todos los sistemas tradicionales de representación social, cuestiona una cierta concepción del delegado, del portavoz autorizado, del líder, del periodista» (Bassets 1981, 233).

5. El primer precedente es la emisión esporádica de Radio Sicilia Libera. A ella le seguirá en 1974 Radio Bologna, la cual da una estructura suficiente para fundar el movimiento de radios libres italiano que, ya en 1979, suma más de 2.500 células de emisión -entre ellas, la mítica Radio Alice-. 
Radio Alice fue el caso más destacable de la experiencia italiana. Emisora ligada al movimiento autónomo, construye un «lenguaje irreverente, creativo, poético, una radio del movimiento, de quien se mueve para cambiar las cosas y a sí mismo (...). Se caracteriza por el rechazo de toda delegación, de todo poder» (Prado 1983, 57-59). Fundada en la pluralidad de voces -de DJ y locutores a sindicalistas-, funciona como una polifonía bajtiniana en la que se mezclan política, filosofía o historia, pero también el rock, la poesía, noticias callejeras y del mundo fabril, hasta bromas, juegos y fábulas infantiles (Figura 1).

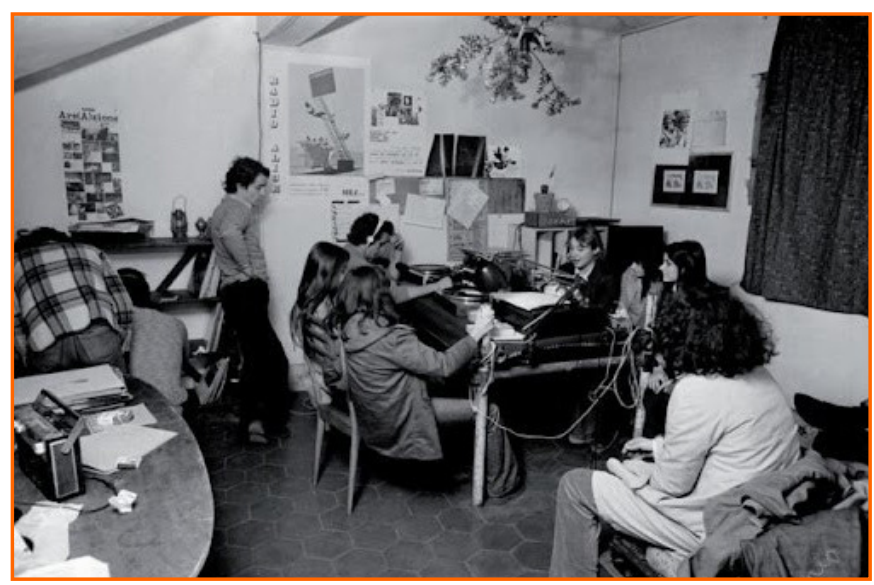

Figura 1. Espacio de emisión de Radio Alice, en una mesa compartida y con funciones distribuidas

Fuente: Fabio Pancaldi, 1977 (publicada en Objects. Rivista online indipendente. Dal 2016: https://www.objectsmag.it/qui-radio-alice-tra-la-creativita-degli-anni-70-e-un-nuovo-mododi-comunicare/)

La emisora se presenta como un «sujeto colectivo de enunciación (...), una subjetividad en movimiento, un proceso de enunciación autónoma» (Bassets 1981, 121/117). No quiere ser un producto informativo, sino modificar la experiencia mediática. No se trata de usar técnicas, sino tecnologías, ni de ser un instrumento, sino un agente comunicativo. El resultado final, tal y como pasó en las radios libres españolas, son centenares de cintas no archivadas debido fundamentalmente a una materialidad cara, necesitada de reciclaje y, por otro lado, a una fiebre por el presente que mitigó la conciencia de estar creando un archivo para la historia.

\section{Video (VT) is not TV}

Entre todas las nuevas prácticas contraculturales de los años setenta, la novedosa técnica del vídeo fue la más exitosa en términos de implantación. El vídeo representó una ruptura tanto con el cine como con la televisión, al crear formas diferentes de producción, distribución y audiencia, y al fomentar el método del «do it yourself/ves». Estas técnicas catalizaron nuevas formas de autoría colectiva que rompieron la eterna división, característica de la televisión, entre arte y cultura popular, entre discurso institucional y discurso de las masas. Como decía el famoso lema de René Berger (Berger 2014), «VT is not TV» (la cinta de vídeo no es la televisión; el vídeo no es televisión). En el aspecto discursivo, el vídeo representaba una amenaza a los otros medios: en lugar de aglutinar en un solo espacio la producción o la difusión, desintegraba su mensaje entre sus usuarios; en lugar de reducir el discurso a una sola voz, fomentó la intercomunicación entre diferentes núcleos de producción, muchos de ellos sin acceso a la producción audiovisual hasta entonces. Además, el deseo de desestabilizar el proceso comunicativo transmisor-mensaje-receptor (artista-obra-espectador) rompió con el principio de originalidad.

La novedad del vídeo, diseñado para ser reciclable e ilimitado, permitió nuevas vías de documentar el mundo cotidiano e investigar nuevas estéticas como el conceptualismo y el minimalismo. Al crear y modificar situaciones, estas prácticas funcionaban como prototipos de investigación -que en otros ámbitos, como las artes escénicas, resultarían en un trabajo alrededor de los cuerpos y de la performance, en lugar del teatro de texto, como en el caso de Comediants, Joglars 0 La Fura dels Baus-. Representaron una nueva relación con el tiempo y con el espacio que supuso un cambio de paradigma en el campo del activismo cultural. Pasaron de la estrategia tradicional de contrainformación a una táctica de transmisión que generaba experiencias constitutivas. ${ }^{6}$ Mientras que las tecnologías del poder ejercían su control sobre el individuo restringiendo la libertad y la imaginación, estas tecnologías del yo (Foucault 1988) promovían nuevas formas de subjetivación al descentralizar e intervenir en la realidad. ${ }^{7}$ Algunos de estos proyectos se desarrollaron en plazas de ciudades, en iglesias y en los mercados, por poner algunos ejemplos de espacio social.

En Barcelona, a finales de los años setenta, surgieron pioneros proyectos de vídeo portátil. Las cámaras de cine y vídeo portátiles, las grabadoras de audio y las unidades móviles ofrecían a los usuarios curiosos una inmediatez, portabilidad y descentralización impensables en los antiguos dispositivos nacionales de Radio Televisión Española, por ejemplo. Los proyectos de videoarte sociocultural, así como los primeros trabajos del artista Antoni Muntadas y colectivos de vídeo comunitario como Video-Nou sacaron provecho de las novedades técnicas y narrativas de esta herramienta: mayores niveles de portabilidad con la aparición del modelo Portapak, ${ }^{8}$ el fin del límite de tiempo en la filmación -se pasó de 10 minutos de negativo a 30060 minutos de cinta magnética

6. En Transmitting Culture (2004), Régis Debray propone el concepto de «transmisión» como un proceso más complejo que la «comunicación» mchuhaniana, entendida simplemente como entrega de información.

7. El concepto de «subjetivización», también en Technologies of the Self: A Seminar with Michel Foucault, designa las técnicas coercitivas que el poder en la modernidad aplicaría a los individuos, en dos direcciones: la individualización y la totalización. La subjetivación implicaba romper la dicotomía entre el sujeto de enunciación, en figuras como el Estado o el mercado, y el objeto de esa enunciación.

8. Desde finales de los años sesenta, Sony comercializaba un modelo realmente revolucionario, el Portapak. 


\section{artnodes}

https://artnodes.uoc.edu

Imaginación radical y anacronía de las imágenes: radios libres y vídeo comunitario en España

-, la capacidad infinita de reciclaje del soporte magnético o la instantaneidad en el proceso de grabación-visionado-edición, entre otros.

El colectivo de videoanimación sociocultural Video-Nou, nacido en Barcelona en 1977, seguía el modelo de descentralización de la producción cultural de pioneros como la británica Fantasy Factory, las televisiones comunitarias y locales en Quebec 0 experiencias radicales como Challenge for Change. Procedentes de la izquierda libertaria, Video-Nou propugnaba la gestión autónoma de espacios como ateneos populares y «centres cívics» de finales de los años setenta en España. El grupo fusionó lo artístico con lo social al aceptar la necesidad de interactuar y aprender de la sociedad civil. Carles Ametller, miembro del grupo, recuerda que «intervenir en la comunicación social venía a significar la posibilidad de construir auténticamente un nuevo espacio público que desarrollara una profundización o intensificación de la democracia en ese tiempo que queda reabierta su conquista» (Ametller 1999), y para eso era crucial "constituirnos como una "comunidad de productores de medios" [en referencia a Bertolt Brecht y Magnus Enzensberger]. Para ello era necesario desarrollar un conjunto de prácticas mediales y políticas capaces de dar autonomía en la esfera pública» (Ibíd.). El vídeo resultó especialmente atractivo por «la libertad y la naturaleza de no manipulación del medio en sí, presentado como el medio de la inmediatez. Además, valoramos el documento, aunque posteriormente resultó limitado. La importancia estaba en el proceso y no en el producto", (Ametller et al. 2016). La técnica del vídeo emitido casi en directo no permitía la manipulación del tiempo y por lo tanto la noción de proyecto era central.

La primera innovación material empleada por Video-Nou fue el Portapak, utilizada con frecuencia entre los círculos de vanguardia en Estados Unidos, Canadá, Alemania o Francia, e introducida en España por el artista Muntadas. El pequeño tamaño de la herramienta y la autonomía que proporcionó redujeron la escala de la producción a no más de dos 0 tres personas: una persona con la cámara, otra mediando entre el dispositivo de grabación y el entrevistado y, a veces, una persona de apoyo. Esta nueva condición material permitió a Video-Nou trabajar en múltiples equipos dando lugar a tres cambios significativos: una producción más dinámica de cada proyecto, la descentralización de temas y formas y, sobre todo, autonomía dentro del grupo. Algunos grupos trabajaron en nuevos proyectos de vanguardia como Vida en común y otros en intervenciones de vídeo sociológico en barrios 0 grupos sociales, pero siempre en pequeños grupos.

La única excepción fue el proyecto fundacional y más innovador del grupo, el Video-Bus. Durante la campaña electoral de 1977, un partido político conservador en Cataluña contrató al grupo de innovadores comunicadores -compuesto por sociólogos, urbanistas, educadores, animadores socioculturales, performers, filósofos e ingenieros - para cubrir la campaña. El grupo decidió dejar de cubrir a los políticos y dar a los ciudadanos, algunos de ellos en pueblos remotos, un papel destacado. Para ello, el grupo alquiló un autobús e, imitando algunos precedentes internacionales, convirtió el medio de transporte en un medio de mesocomunicación. El dispositivo fue concebido como una red de elementos para lograr la acción comunicativa descentralizadora: movilidad, inmediatez y retroalimentación. Los miembros del grupo aportaron sus conocimientos específicos: el diseño arquitectónico del dispositivo, las conexiones técnicas requeridas y el diseño de la estrategia sociológica, entre otros (Figura 2).

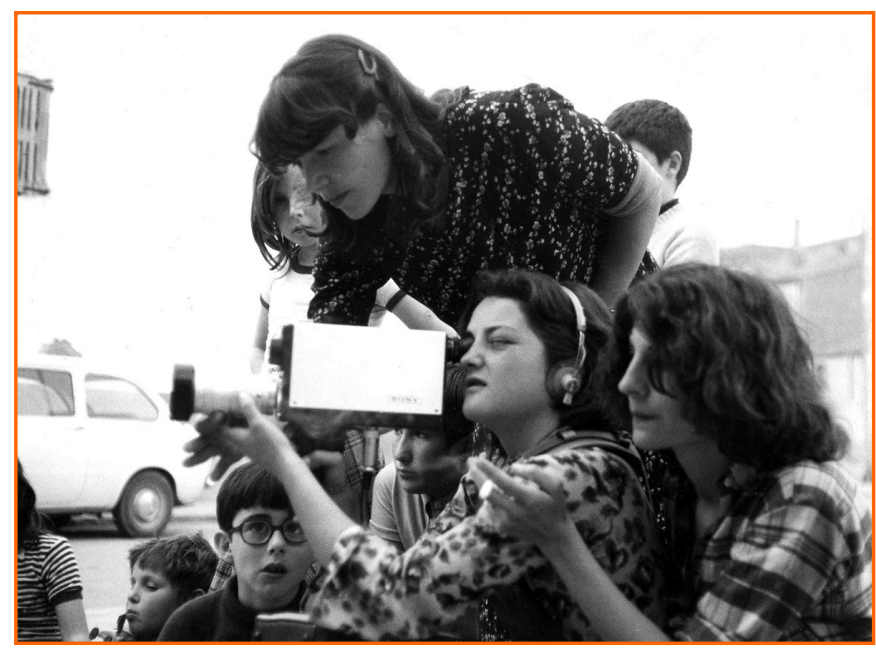

Figura 2. Un equipo ligero de producción de Video-Nou registra imágenes con el Portapak para el proyecto del Video-Bus durante la campaña para la Lliga de Catalunya (Girona). Fuente: Video-Nou, 1977.

Ese extraño vehículo se convertiría en una alternativa pionera en el país a las pesadas unidades móviles de Televisión Española y el resultado de sus experiencias, en pequeños actos de sabotaje informativo. Desestabilizaron el discurso institucional y se reapropiaron del lugar de la enunciación de forma antagónica. El Video-Bus demostró cómo un dispositivo tecnológico puede ser simultáneamente una transmisión de prácticas. Video-Nou convirtió una maquinaria de producción audiovisual en un dispositivo de discurso integral, que incluiría producción, edición, exhibición, retroalimentación, discusión y finalmente reedición.

\section{Conclusión}

Los casos estudiados en este artículo -desde los colectivos de Video-Nou y Servei de Vídeo Comunitari hasta el fenómeno popular de las radios libres- se enmarcan en una tradición minoritoria, aunque no subestimable, de prácticas mesocomunicativas que empieza en el tardofranquismo con el cine amateury el cine militante ya dominante en Cataluña, País Vasco y Madrid. ${ }^{9}$ Esta línea se interrumpe en la mayoría de los casos con la cooptación del videoarte por parte de las institucio-

9. Para un estudio a fondo tanto del cine militante como de la escena del videoarte, consultar Desacuerdos 4: Sobre arte, políticas y esfera pública en el Estado español. Cine y vídeo (VV. AA. 2007) 0 Central del Curt. Cooperativa Cinema Alternatiu (1974-82) (Martí Rom 1994). 
nes museísticas y del vídeo y radio comunitarios por instituciones municipales y regionales que, en gran medida, anulan las prácticas comunitarias de finales de los años setenta. No será hasta finales de los años noventa cuando las prácticas mediaactivistas vuelvan a adquirir cierto protagonismo como respuesta a los movimientos antiglobalización de finales de siglo, con casos legendarios como redes pioneras de información digital como Indymedia, o nuevas plataformas de «altermediation» en formatos de radio, televisión e internet (sobre todo en Italia). Prácticas similares surgieron a raíz de la crisis de representación política durante la década pasada (20112020). No estamos ante la desaparición del músculo social sino ante la reducción de dispositivos de visibilidad sostenibles en el tiempo.

Por ser locales y situadas, este tipo de prácticas eran constitutivas de compromiso, transformación y justicia. Frente a los aparatos comunicativos del Estado, se alejaban de la mediación simbólica y pasaban a la acción. En consecuencia, pueden ser leídas como expresiones de una racionalidad radical basada en un equilibrio entre compromiso ético y experiencia estética -enfocándose más en el proceso y el prototipo que en producto narrativo- desde la comunidad, con intimidad e imaginación. Al apropiarse del espacio físico y romper con el habitus creado por la subjetivación hegemónica, desarrollaron lo que Michel de Certeau definió en La invención de lo cotidiano como «el arte del débil» (De Certeau 2000).

Estas prácticas de comunicación colectiva representan un claro precedente de las lógicas dominantes de la era digital: por un lado, la necesidad de colaboración para llevar a cabo prácticas con un mayor impacto; por otro, conciencian a los ciudadanos de su propia capacidad de enunciación y avanzan en la democratización de la educación audiovisual. Sin embargo, también advierten de la tendencia de las instituciones políticas para cooptar su potencial emancipador y para desmantelar sus lógicas descentralizadoras. Así, hoy, frente a la retórica de la inevitabilidad distópica, es necesario y posible repensar la función de prototipos como Twitter o bien articular nuevos prototipos y prácticas de imaginación radical que, como los expuestos en este artículo, discutan el discurrir de su tiempo.

Lo que se ha argumentado en este ensayo es que el campo de las artes y la comunicación, tanto en sus procesos como en su resultado material, pueden anticiparse al ámbito de lo social. Aun siendo prácticas contraculturales bajo diferentes regímenes políticos, todas representan un deseo de intervenir en la sociedad. Las utopías prometeicas de la modernidad terminaron barridas por las utopías aceleracionistas del capitalismo y, en el momento actual, por las distopías de la ficción. El momento actual exige imaginar nuevos mundos colectivos desde la realidad, siendo esencial el regreso al ágora pública y a la materialidad. Si resultó que el VT no era la TV, tal vez se pueda afirmar que la $\mathrm{Net}$-las redes, en todas sus dimensiones- ya no es solamente internet. ${ }^{10}$

\section{Referencias bibliográficas}

Ametller, Carles. 1999. «Por una comunicación contextual. La experiencia de Video-Nou / Servei de Video Comunitari.» Banda aparte, no.16 (1999): 45-48.

Ameller, Carles et al. «De las videoutopías a la institucionalización (I).» Entrevista de Ignasi Gozalo Salellas. Julio 2016. Video, 2016.

Bassets, Lluís (ed.). De las ondas rojas a las radios libres. Barcelona: Gustavo Gili, 1981.

Bauman, Zygmunt. Retrotopia. Barcelona: Arcàdia, 2017.

Berardi, Franco, Jacquemet, Marco, Vitali, Giancarlo. Telestreet: Máquina imaginativa no homologada. España: El Viejo Topo, 2003.

Berger, René et al. René Berger: L'art Video. Génova: JRPIRingier, 2014.

Castoriadis, Cornelius. «Imaginación, imaginario, reflexión.» Ontología de la creación (1997): 131-212. Santa Fe de Bogotá: Ensayo y error.

Castoriadis, Cornelius. La institución imaginaria de la sociedad. Buenos Aires: Tusquets Editores, 2007.

De Certeau, Michel. La invención de lo cotidiano. México D.F.: Universidad Iberoamericana, Departamento de Historia, 2000.

Debray, Régis. Transmitting Culture. Nueva York: Columbia University Press, 2004.

Didi-Huberman, Georges. Ante el tiempo. Historia del tiempo y anacronismo de las imágenes. Buenos Aires: Adriana Hidalgo editora, 2008.

Didi-Huberman, Georges. Imágenes pese a todo. Barcelona: Paidós, 2004.

Foucault, Michel. Technologies of the Self. A Seminar with Michel Foucault. Londres: MIT Press, 1988.

Foucault, Michel. The Care of the Self. Volume 3 of The History of Sexuality. Nueva York: Pantheon Books, 1986.

Garcés, Marina. «Condición póstuma» (2019). Modificado por última vez 17 de abril, 2019. https://www.arquine.com/condicion-postuma.

Garcés, Marina. Nueva Ilustración Radical. Barcelona: Anagrama, 2017. Guattari, Félix. Plan sobre el planeta: Capitalismo mundial integrado y revoluciones moleculares. Madrid: Traficantes de sueños, 2004.

Gubern, Román. «Megacomunicación vs. Mesocomunicación.» Telos, no. 3 (1985). 


\section{artnodes}

Hardt, Michael, Negri, Toni. «Negri - Hart y el Movimiento Operario Italiano.» Nómadas | Revista Crítica de Ciencias Sociales y Jurídicas (2003). Universidad Complutense de Madrid. 1 de enero. Web.

Martí Rom, Josep-Miquel. La Central del Curt. Cooperativa Cinema Alternatiu (1974-82): Una experiencia alternativa. Barcelona: Filmoteca de Catalunya, 1994.

Prado, Emilio. Las radios libres. Teoría y práctica de un movimiento alternativo. Barcelona: Editorial Mitre, 1983.

Traverso, Enzo. Left-wing melancholia: Marxism, history and memory. Nueva York: Columbia University Press, 2016. DOl: https://doi. org/10.7312/trav17942.
Traverso, Enzo. Melancolía de izquierda: Después de las utopías. BarceIona: Galaxia Gutenberg, 2019.

VAA. Desacuerdos 4: Sobre arte, políticas y esfera pública en el Estado español. Cine y vídeo. Barcelona: Arteleku-Diputación Foral de Gipuzkoa, Centro José Guerrero - Diputación de Granada, Museu d'Art Contemporani de Barcelona y UNIA arteypensamiento, 2007.

WAA. En torno a en torno al vídeo. Vitoria: Centro Cultural Montehermoso, 2010

WAA. En torno al vídeo. Abadiño: Servicio Editorial De La Universidad Del País Vasco, 2010. 


\section{artnodes}

\section{CV}

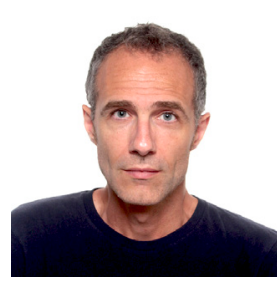

\section{Ignasi Gozalo Salellas}

Universitat Oberta de Catalunya

Bryn Mawr College

igozalo@uoc.edu

Doctor en Filosofía por la Universidad de Pennsylvania (EE. UU.). Ha sido profesor en esa institución, así como en Bryn Mawr College y la Universidad de Ohio State. Actualmente, es profesor en los Estudios de Ciencias de la Información y de la Comunicación y en el máster de Filosofía para los Retos Contemporáneos de la Universitat Oberta de Catalunya, de la que es asimismo miembro del grupo de investigación MUSSOL.

Su trabajo transita entre la filosofía y la cultura visual, con especial foco en la arqueología de medios en España y el sur continental. Es coautor de la serie audiovisual Qué hacer: América en la era Trump (2018) y del libro EI síndrome Trump (2019), así como editor de los dosieres América en crisis y La década destituyente (La Maleta de Portbou, 2020-2022). Sus artículos han sido publicados en revistas y editoriales como Toronto University Press, Boundary 2, Modern Languages Notes, ReFocus, Hispanic Review, 452 ${ }^{\circ} \mathrm{F}$ o Hispanófila. Además de su carrera académica, Ignasi Gozalo-Salellas es realizador audiovisual con extensa experiencia en televisión y publicidad. Publica en medios españoles como La Maleta de Portbou, CTXT, Público, La Marea, Ara, FronteraD y l'Espill.nte, una de sus piezas ha sido incorporada a la .BEEP \{collection;\} de arte electrónico. 